\title{
Harmonizing Europe's payment systems: an uphill battle?
}

Citation for published version (APA):

Leibbrandt, G. (2004). Harmonizing Europe's payment systems: an uphill battle? MERIT, Maastricht Economic Research Institute on Innovation and Technology. MERIT-Infonomics Research Memorandum Series No. 020 https://doi.org/10.26481/umamer.2004020

Document status and date:

Published: 01/01/2004

DOI:

10.26481/umamer.2004020

Document Version:

Publisher's PDF, also known as Version of record

\section{Please check the document version of this publication:}

- A submitted manuscript is the version of the article upon submission and before peer-review. There can be important differences between the submitted version and the official published version of record.

People interested in the research are advised to contact the author for the final version of the publication, or visit the DOI to the publisher's website.

- The final author version and the galley proof are versions of the publication after peer review.

- The final published version features the final layout of the paper including the volume, issue and page numbers.

Link to publication

\footnotetext{
General rights rights.

- You may freely distribute the URL identifying the publication in the public portal. please follow below link for the End User Agreement:

www.umlib.nl/taverne-license

Take down policy

If you believe that this document breaches copyright please contact us at:

repository@maastrichtuniversity.nl

providing details and we will investigate your claim.
}

Copyright and moral rights for the publications made accessible in the public portal are retained by the authors and/or other copyright owners and it is a condition of accessing publications that users recognise and abide by the legal requirements associated with these

- Users may download and print one copy of any publication from the public portal for the purpose of private study or research.

- You may not further distribute the material or use it for any profit-making activity or commercial gain

If the publication is distributed under the terms of Article $25 \mathrm{fa}$ of the Dutch Copyright Act, indicated by the "Taverne" license above, 


\section{MERIT-Infonomics Research Memorandum series}

Harmonizing Europe's payment systems: an uphill battle?

\section{Gottfried Leibbrandt}

2004-020

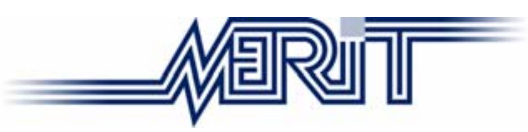

MERIT - Maastricht Economic Research Institute on Innovation and Technology

PO Box 616

6200 MD Maastricht

The Netherlands

T: +31433883875

F: +31433884905

http://www.merit.unimaas.nl

e-mail:secr-merit@merit.unimaas.nl

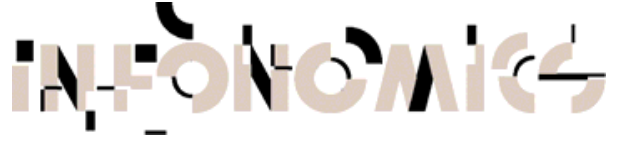

International Institute of Infonomics

c/o Maastricht University

PO Box 616

6200 MD Maastricht

The Netherlands

T: +31 433883875

F: +31453884905

http://www.infonomics.nl e-mail: secr@infonomics.nl 


\title{
Harmonizing Europe's payment systems: an uphill battle?
}

\author{
Gottfried Leibbrandt* \\ Merit, University of Maastricht
}

September 22, 2004

\begin{abstract}
A model is introduced to analyze the effect of network effects and transactions patterns on the decision by banks (not) to standardize payment systems both domestically and across borders. If only a small share of all transactions is cross-border, banks have strong incentives to maintain incompatible standards across countries. The model is applied to the case of harmonizing Europe's payment networks.
\end{abstract}

\section{Introduction}

Aligning Europe's many national standards and networks is an important challenge in the quest for a common market. Credit transfer payment systems, for example, are still national: in spite of the common currency it is much easier to transfer money from Lille to Marseille (1000 $\mathrm{km})$ than across the Belgian border to Kortrijk $(30 \mathrm{~km}){ }^{1}$

This lack of European standardization is important because it hinders intra-Europe commerce. It also forms a barrier against cross-border entry of banks. A bank in country $A$ cannot offer retail products in country $B$ without having some form of access to the payment system in that country: its customers will need access to their savings accounts

*This paper resulted from a discussion at the 23rd SUERF symposium in Brussels. Comments and suggestions by Arnout Boot, Robin Cowan, Martin Fase, Leo van Hove, and Steven Ongena are greatfully acknowledged.

${ }^{1}$ Credit transfers comprise payments where a client instructs his bank to transfer money to the account of someone else, not necessarily with the same bank. The category includes direct debits, where the payee (generally a company, for example an electrical utility) instructs his bank to take the money out of the account of the payee. 
and they will want to transfer money from their salary accounts to pay their bills. Such access generally requires a (substantial) local presence with set-up costs, etc.

There is both theoretical and empirical evidence that lack of crossborder entry reduces welfare. Hoschka (1993) provides a theoretical model to analyze the effect on cross-border entry on the domestic deposit market, and finds that cross-border entry can (1) increase price competition, (2) reduce $\mathrm{X}$-inefficiencies, (3) spoil collusive domestic equilibria, and (4) increase the quality and variety of services.

Berger, DeYoung, et al. (2000) survey the empirical literature on bank efficiency, and find (1) a substantial dispersion among efficiencies (X-inefficiencies) both within and across countries, (2) a clear reduction of X-inefficiencies in a country after the entry of foreign competitors. ${ }^{2}$

Cecchini (1988) quantifies the yearly benefits of full competition among European financial service providers at 22 billion ECU. ${ }^{3}$ Sixteen years, and many common market initiatives later, there is little doubt that European retail banking markets remain highly local. Kleimeier and Sandor (2003), for example, examine retail deposit and lending rates in 10 European countries, and conclude that the European market for retail banking products remains fragmented.

This paper models payment systems as economic networks and reformulates the (lack of) a common payment system as a compatibility issue. It introduces a model to analyze the compatibility decision in a 2-country setting. The model explicitly considers payment transactions patterns. In practice, these patterns are highly national. Less than $1 \%$ of all credit transfer payments, and about $5 \%$ of all card and cash payments are cross-border, the rest is domestic. As the overview in table 1 shows, the same is true for other networks like mail and telephony. The analysis and model in this paper can therefore be equally applied to other network sectors like telecommunication.

The main result of the model is that transaction patterns crucially affect the compatibility decision. With random patterns, firms always prefer compatible standards. This result changes radically if transaction patterns are semi-autarkic. Firms will then generally prefer incompatibility, even in the absence of migration costs.

This paper proceeds as follows. Section 2 analyzes the literature

\footnotetext{
${ }^{2}$ Berger, De Young, et al. talk of X-efficiencies, while Hoschka prefers Xinefficiencies. This paper uses the latter term.

${ }^{3}$ About 30 billion Euro in today's money. This figure is derived by assuming that for each financial product (loans, mortgages, savings, etc.) prices in all European countries would migrate to those in the country with the best prices (lowest interest rates for loans and mortgages, highest for savings).
} 


\begin{tabular}{llll}
\hline Category & Unit & Int'l traffic & Countries included \\
\hline $\begin{array}{l}\text { Surface mail } \\
\text { Telephony }\end{array}$ & Letters received & $1.5 \%$ & Global average \\
- Fixed line & Call minutes & & \\
- GSM & & $1-1.5 \%$ & US \\
Payments & Transactions & & Scandinavia \\
- Credit transfers & & $0.5 \%$ & EU, US, Can, Japan \\
- Credit/Debit cards & & $5 \%$ & EU \\
- Cash & & $5 \%$ & Euro zone \\
\hline
\end{tabular}

Table 1: Cross-border traffic as a percentage of all traffic.

Source: mail data from UPU (2004), fixed telephony data from FCC (2003), Telestatistik (2000) and TeliaSonera (2003), GSM data from Telestatistik (2000), transfer payment data from BIS (2004) and ECB (2003), card payment data based on McKinsey analysis of Visa and MasterCard data, cash estimate based on Euronote diffusion figures (analysis available from the author).

on transaction patterns and network effects. Sections 3 introduces a model to analyze the effect of national patterns on the harmonization of sponsored standards. Section 4 applies the model to the (lack of) harmonization of European systems for making credit transfer payments. Section 5 discusses the results.

\section{Literature}

There is ample evidence that standards and in particular payment systems are subject to increasing returns, where each user makes the standard or network more valuable to other (potential) users. ${ }^{4}$ Empirical studies confirm the existence of network externalities for ATMs (Saloner and Shepard, 1995, and Sharma, 1993), ACH-transfers (Gowrisankaran and Stavins, 2002), and debit and credit cards (Stavins, 2001, and Mantel and McHugh, 2001).

A wide body of literature analyzes the adoption and compatibility of network technologies. The literature generally makes a distinction between sponsored standards, which can be owned and controlled by firms (e.g. video formats like VHS and Betamax), and unsponsored standards, which are open to all (e.g. the fax protocol). Payment system standards are generally sponsored, hence the remainder of this section will focus on

\footnotetext{
${ }^{4}$ For a recent overview of the topic, see the June 2003 issue of the Review of Network Economics, which was entirely dedicated to network effects in payment systems.
} 
the sponsored standards literature. ${ }^{5}$ Furthermore, payment systems are mostly adopted by firms (banks) that compete monopolistically by offering differentiated products. The 'Mix \& Match' model of Matutes and Regibeau (1988) analyzes the compatibility decision by 2 firms that offer differentiated network goods. They find that in equilibrium firms prefer compatibility. Shy (2001) models the compatibility decision by firms whose customers face switching costs. If one firm sufficiently undercuts the price of the other firm, compensating customers for switching costs, it can lure them away from its competitors. Shy too finds that, if the product is subject to network effects, compatibility is the equilibrium outcome.

All of these models assume random transaction patterns, where each additional user is equally relevant to the existing customer base. As the previous section shows, however, this is not the case for many networks. Foreign users are generally less relevant than other users in the same country. Relatively little attention has been devoted to the effect of such spatial transaction patterns. And the few examples that do, focus on unsponsored standards. For example, Ellison (1993) analyses agents located on a circle. These agents face a choice between two standards, preferring the standard of their immediate neighbors. Given sufficient local externalities, the system will converge to universal compatibility, where all agents use the same standard. Cowan and Cowan (1998) model agents on a lattice. These too face a choice between two standards, again preferring the standard of their immediate neighbor. In addition to this local positive externality, however, the authors introduce a global negative externality. This leads to coexistence of standards, where each standard occupies an enclave or region. Both models assume homogeneous landscapes without borders. As a result, the enclaves of Cowan and Cowan drift across the lattice as the model iterates. In real life, however, the enclaves tend to be countries, which are geographically fixed. The model of Bassanini and Dosi (1998) does explicitly consider 'countries'. They apply a Polya urn model to an environment with multiple interacting pools of consumers, and find that different outcomes can occur for different pools, in line with the observed reality of national standards. The Polya urn model, however, analyzes the adoption of unsponsored standards. Furthermore, it focuses entirely on the initial adoption; it does not consider subsequent migration to a common standard.

In summary, there are good models to analyze the compatibility de-

\footnotetext{
${ }^{5}$ Banks can generally control access to their networks. For example they can deny access to their ATMs. Similarly, membership of credit and debit card networks has been subject to fees and conditions.
} 
cision for sponsored standards, as long as agents interact randomly. The effect of national transaction patterns, however, remains to be explored. The next section introduces a model to do just that.

\section{The model}

The basic model assumes Section 3.1 assumes random transaction patterns, and in that case the model leads to similar results as other models for monopolistic competition between two firms offering differentiated products: both firms prefer to establish compatibility in equilibrium. ${ }^{6}$ These outcomes then serve as a reference to analyze the impact of nonrandom transaction patterns in section 3.2.

\subsection{Basic model with random transaction patterns}

Two firms, $A$ and $B$, are located at either end of the unit interval and compete à la Hotelling. Each customer buys exactly one unit of the good from the firm that offers the lowest price corrected for transportation cost, which are equal to $t$ per unit of distance between the customer and the supplying firm. Without loss of generality the number of customers is normalized to one, and marginal costs to zero. Let $p_{i}, s_{i}$ and $\pi_{i}$, $i \in\{A, B\}$, be the price, market share and profit of the two firms. The equilibrium values of these parameters, denoted with an asterisk $\left(^{*}\right)$, can be derived using the standard Hotelling approach. The market shares are defined by the marginal customer who is indifferent between buying from either firm, because their net prices, corrected for transportation costs are equal:

$$
p_{i}+s_{i} t=p_{j}+\left(1-s_{i}\right) t \Leftrightarrow s_{i}=\frac{p_{j}-p_{i}+t}{2 t} .
$$

Profits are then:

$$
\pi_{i}=p_{i} s_{i}=\frac{p_{i} p_{j}-p_{i}^{2}+p_{i} t}{2 t}
$$

The first order condition for profit maximization is:

$$
\frac{\partial \pi_{i}}{\partial p_{i}}=\frac{p_{j}-2 p_{i}+t}{2 t}=0 .
$$

\footnotetext{
${ }^{6}$ Other models are Matutes and Regibeau (1988) and Shy (2001). These, however, cannot easily deal with non-random transaction patterns.
} 
Since equilibrium is symmetrical, this leads to the standard Hotelling result:

$$
\begin{aligned}
p^{*} & =t \\
s^{*} & =\frac{1}{2} \\
\pi^{*} & =\frac{t}{2} .
\end{aligned}
$$

Assume now that the goods offered are subject to network benefits $b$ per user of the network. Without loss of generality, both the number of consumers and unit transportation costs, $t$, are normalized to one $(b$ should be expressed as a multiple of $t$ ). Each firm offers a proprietary standard to its consumers, unless both firms decide to offer each other compatibility. If the goods of the two firms are incompatible, each good offers network benefits equal to $b s_{i}$ (since the number of consumers is normalized to one). To reflect these effects we can define hedonic prices $\hat{p}_{i}$ that are corrected for network benefits:

$$
\begin{aligned}
& \hat{p}_{i} \equiv p_{i}-b \quad \text { if the networks of } A \text { and } B \text { are compatible } \\
& \hat{p}_{i} \equiv p_{i}-b s_{i} \text { if they are not. }
\end{aligned}
$$

If both networks are compatible, hedonic prices as defined in (3) can be substituted into (1). Because the network benefits are the same for the product of both firms (since their networks are compatible) the corresponding terms 'cancel out', and equilibrium prices and profits are the same as without the network effect. ${ }^{7}$

If networks are incompatible we have to substitute (4) instead of (3) into (1):

$$
p_{i}+b s_{i}=p_{j}+b\left(1-s_{i}\right) \Leftrightarrow s_{i}=\frac{p_{j}-p_{i}+1-b}{2(1-b)} .
$$

The system now has an internal solution iff $b<1$; for $b>1$ the market 'tips': either firm captures the whole market. ${ }^{8}$

\footnotetext{
${ }^{7}$ Since $\hat{p}_{i}^{*} \equiv p_{i}^{*}-b=1-b$, the full network benefit accrues to the consumer. The network benefits are equal for both firms, and thus they act exactly like the marginal costs in the original Hotelling model (but in the opposite direction): they affect consumer welfare, but not firm profits.

${ }^{8}$ This result was obtained for a wide class of differentiated network good models by DePalma and Leruth (1993). The essence of their proof is that if $b>t$ the network benefits exceed the transportation costs even for the most distant customer. All customers thus join the largest network and the system 'tips' to the standard
} 
If $b<1$ we can use the standard Hotelling approach and substitute the above expression in the profit function $\left(\pi_{i}=p_{i} s_{i}\right)$. By then taking the first order condition we get the following symmetrical equilibrium:

$$
\begin{aligned}
p^{*} & =1-b \\
s^{*} & =\frac{1}{2} \\
\pi^{*} & =\frac{1}{2}-\frac{1}{2} b .
\end{aligned}
$$

By comparing (5) with (2) it follows that prices and profits are lower compared to the situation where both firms offer compatible network products. Following the literature we can model firm actions as a twostage game. In stage 1 each firm decides whether to offer and accept compatibility with the other firm. Compatibility is only established of both firms agree. In stage 2 they compete on price. It then follows that the unique (Nash) equilibrium outcome is that the two firms establish compatibility, because profits for both firms are always higher under compatibility. This outcome also maximizes welfare. Compatibility raises firm profits by $b$, while it reduces the hedonic price to consumers by $\frac{b}{2}$, leading to a net welfare gain of $\frac{b}{2}$.

Result 1 With homogenous transaction patterns, two firms will settle on compatibility, which is also the socially optimal solution.

This basic result can now be used as a benchmark for analyzing what happens if transactions patterns are highly national (as shown by table 1). ${ }^{9}$

\subsection{The effect of autarkic transaction patterns}

Let the above Hotelling model be adapted as follows. The unit interval is divided into two halves ('countries') of equal size. If transaction pat-

of either firm: an increase in the share of a firm increases the network benefits to a user by an amount larger than the increase in transportation cost for the marginal consumer. Instead of an internal solution where two incompatible standards share the market, there are now two corner solutions where either firm captures the whole market.

${ }^{9}$ As discussed earlier, this result is in line with other models of differentiated network goods, like those of Matutes and Regibeau (1988) and Shy (2001). The reason for not picking either of these two models, is that neither model can be extended to deal with national transaction patterns. Matutes and Regibeau's Mix \& Match model analyzes the combination of two components (as in hifi-equipment or cameras and lenses). Shy's model could be adapted to analyze two countries. There is however no differentiation between consumers in a country: they either all stick to the current provider, or all switch to another. Thus a situation where only some consumers use a foreign standard never occurs. 
terns were random, each customer would perform half of his transactions (payments, phone calls etc.) with other customers in his own country (i.e. his own half of the unit interval), and the other half of his transactions with customers in the other country. Assume instead that the two halves are somewhat autarkic: customers on each half of the interval transact mostly within their own half of the unit interval. Consider, for example, consumers of Elzas-Lorraine. They could well be somewhere between France and Germany in 'taste-space'; yet most of their transactions will be within France (paying Gaz de France, France Telecom, taxes, etc.). Assume that instead of half their transactions, consumers perform only a fraction $\frac{\delta}{2}$ of their transactions with consumers in the other 'country', and a fraction $1-\frac{\delta}{2}$ with consumers in their own country. Here $\delta=1$ corresponds to random interaction, and $\delta=0$ represents complete autarky (i.e. consumers transact only with consumers on their own side of the interval).

If $\delta<1$, the equilibrium outcomes of the model are as follows (they are derived in the appendix):

$$
\begin{aligned}
p^{*} & =1-b+\sqrt{D} \\
s^{*} & =\frac{1}{2} \\
\pi^{*} & =\frac{1}{2}-\frac{1}{2}(b+\sqrt{D}) .
\end{aligned}
$$

The variable $D$ captures the autarky effect:

$$
D=\{1-b\}^{2}-\{1-b(3-2 \delta)\}^{2} .
$$

Note that for $\delta=1$ we get $D=0$, and (6) reduces to (5), the equilibrium outcomes for random transaction patterns.

For $\delta<1$, firms will prefer compatibility if $b-\sqrt{D}>0$. After some rearrangement of terms, this condition can be written as:

$$
b>\frac{4(1-\delta)}{(3-2 \delta)^{2}}
$$

This is the lower curve in figure 1. For values of $b$ below this curve, duopolists prefer incompatibility. The figure also shows the curve $b=$ $\frac{1}{2-\delta}$. For values of $b$ above this curve, the DePalma and Leruth (1993) condition is no longer met, and the system 'tips' if firms maintain incompatible standards. Note that if $\delta=1$ and $0<b<1$, duopolists always prefer compatibility over incompatibility, in line with the results of section 3.1. For smaller $\delta$, however, duopolists on either side of a border increasingly prefer incompatibility. 


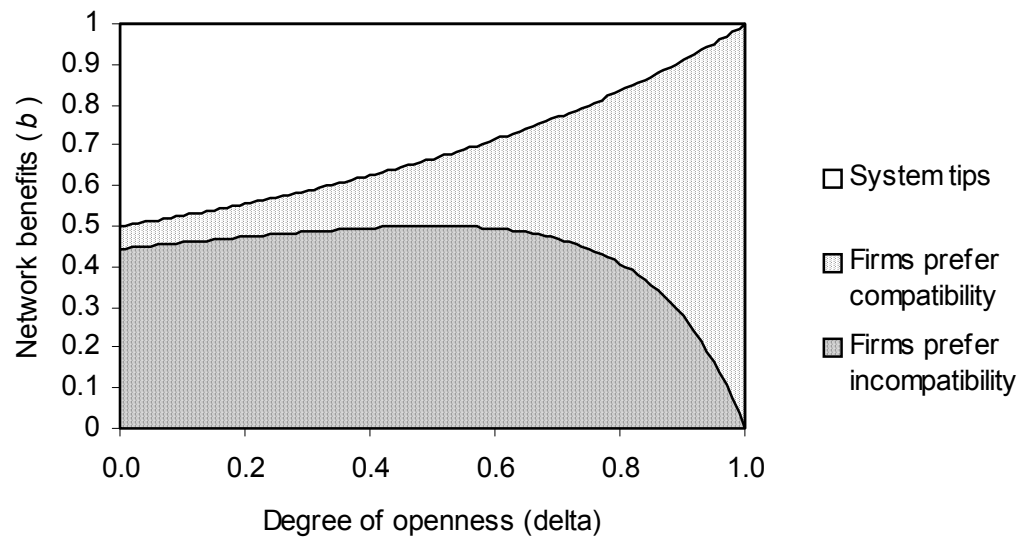

Figure 1: Range of values of $b$ and $\delta$ where firms prefer (in)compatibility, transaction patterns are not random but semi-autarkic $(\delta<1)$

Result 2 For $\delta<1$ and $b<1$, firms on either side of a border make the following (in) compatibility decision:

1. If $b<\frac{4(1-\delta)}{(3-2 \delta)^{2}}$ both firms prefer to maintain incompatible versions.

2. If $\frac{4(1-\delta)}{(3-2 \delta)^{2}}>b>\frac{1}{2-\delta}$ the equilibrium is the same as with random transaction patterns: both firms prefer compatibility.

3. If $b>\frac{1}{2-\delta}$ the DePalma-Leruth condition for coexistence of incompatible networks is no longer met.

When $b$ is low compared to $\delta$ firms prefer incompatibility, because the network benefits of compatibility are smaller than the gains from the decreased competition resulting from incompatible standards across borders. For intermediate values of $b$, the network benefits of compatibility dominate and we get the (familiar) result that both firms prefer compatibility. For high values of $b$ the nature of the 'game' changes to winner takes all, if firms maintain incompatibility; Depending on the risk profile of either firm, and their estimate of the chances to win this battle, they may prefer to fight it out rather than establish compatibility.

What causes this sudden desire for incompatibility by firms? The semi-autarkic transaction pattern creates a natural border. This border softens competition by insulating both players against each other's competition. 


\begin{tabular}{rrrr}
\hline & Incompatibility & Compatibility & Gain \\
\hline$W_{f}$ & $1-b+\sqrt{D}$ & 1 & $b-\sqrt{D}$ \\
$W_{c}$ & $-(1-b+\sqrt{D})+\left(1-\frac{\delta}{2}\right) b$ & $-1+b$ & $-\left(1-\frac{\delta}{2}\right) b+\sqrt{D}$ \\
$W_{s}$ & $\left(1-\frac{\delta}{2}\right) b$ & $b$ & $\frac{\delta}{2} b$ \\
\hline
\end{tabular}

Table 2: Welfare effects of compatibility decision

\subsection{Welfare analysis}

Table 2 summarizes the welfare impact of the compatibility decision. Firm welfare, $W_{f}$, is the sum of firm profits. Consumer welfare, $W_{c}$, is defined as minus the hedonic price, while social welfare, $W_{s}$, is simply $W_{f}+W_{c}$.

It is useful to first consider the polar cases of random transaction patterns $(\delta=1)$ and total autarky $(\delta=0)$, and then look at the intermediate case.

Random transaction patterns $(\delta=1)$. In that case $D=0$ and the gain from establishing compatibility is always positive for both firms, making it the unique equilibrium outcome. Consumers are worse off under compatibility, since prices rise by $b$, while their network benefits only increase by $\frac{b}{2}$. But since firms gain twice as much as consumers lose, the overall welfare is higher under compatibility. Thus the equilibrium outcome is also the socially desirable outcome.

Complete autarky $(\delta=0)$. The compatibility decision does not impact social welfare. It does however transfer welfare between firms and consumers. Firms gain from incompatibility if $0<b<\frac{4}{9}$. Their gain, $b-\sqrt{D}$, represents a pure welfare transfer from consumers to firms (compared to a situation of compatibility). This transfer is 0 for $b=0$ and $b=\frac{4}{9}$, reaching a maximum value of $\frac{1}{2}$ for $b=\frac{1}{6}$. Hence for very low $\delta$, firms may have a very large incentive to prefer incompatibility, leading to an equally large loss for consumers.

Some autarky $(0<\delta<1)$. Incompatibility leads to a welfare loss of $\frac{\delta}{2} b$. If firms prefer incompatibility, they do so because it raises their profit. Hence consumers must face a loss that is bigger than the social welfare loss (since firms gain from incompatibility). As $\delta$ grows (countries are more connected) so does the loss in social welfare, reaching a maximum of $\frac{1}{6}$ for $\delta=\frac{3}{4}$ and $b=\frac{4}{9} \cdot{ }^{10}$ The loss to consumers, by contrast, goes down as $\delta$ increases, because this diminishes the dampening effect on competition.

\footnotetext{
${ }^{10}$ This is the maximum welfare loss subject to the constraint that firms indeed prefer incompatibility, i.e. $b<\frac{4(1-\delta)}{(3-2 \delta)}$.
} 
Result 3 When transaction patterns are highly autarkic, incompatibility leads to a substantial loss in consumer welfare and a modest loss in social welfare. For more integrated patterns (large $\delta$ ) incompatibility may lead to substantial losses in both social and consumer welfare.

An important feature of the model is that it assumes fixed demand and takes firm cost structures as given (both are basic features of the underlying Hotelling model). This means that the loss in social welfare is entirely due to the direct impact of incompatibility, which reduces the network benefits to consumers and society as a whole. Because demand is fixed, the lack of competition does not lead to the 'deadweight loss' associated with a monopoly. And because cost structures are given, competition does not reduce X-inefficiencies. Hence the model underestimates the social losses due to incompatibility.

There is empirical evidence that the price sensitivity of the demand for payment services is indeed low. Using cross-country data, Humphrey, Pulley, et al. (1996) find own price elasticities of 0.09-0.26; Murphy (1991) finds that per item charges on checks reduce usage by only $10 \%$; and several authors have been puzzled by the willingness of consumers to pay high interest rates on credit card debt. ${ }^{11}$

The second assumption (cost structures are given) gets much less empirical support. As discussed earlier, the survey by Berger DeYoung, et al. (2000) strongly suggests that foreign competition significantly reduces X-inefficiencies. This would imply that the social loss from incompatibility is larger than the model suggests.

\subsection{Impact of migration costs on harmonization}

In some cases compatibility can be established by 'flipping a switch', by opening up a network. In other cases, however, migration involves real costs, such as educating consumers, issuing new cards, assigning new (account) numbers etc.

Let $c$ denote the cost of migrating a single user to another version of the network technology. The earlier analysis implicitly assumed $c=$ 0 . If $c>0$ this poses an additional hurdle for firms that start with incompatible standards and want to make them compatible. Either firm

\footnotetext{
${ }^{11}$ Humphrey, Kim, et al. (2001) analyze the impact of prices on payment instrument usage in Norway. They find much higher own price elasticities: $0.75-0.96$. However, it is not clear that the dramatic substitution of checks by electronic payments was (solely) due to pricing, since the Netherlands, for example, witnessed a similarly rapid substitution without the introduction of e.g. a consumer charge per check.
} 


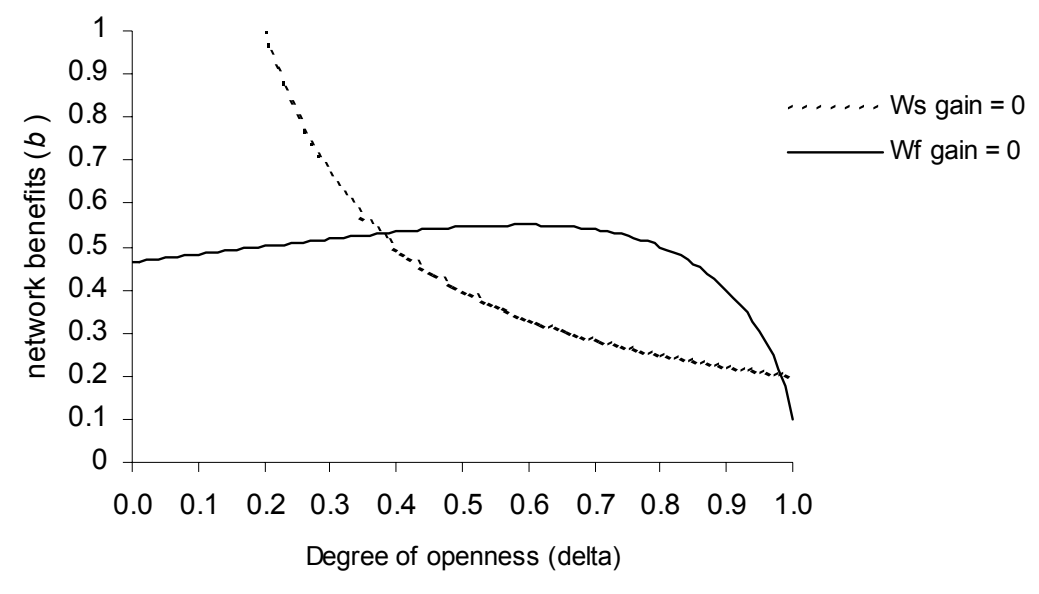

Figure 2: Occurrence of excess inertia as a function of autarky and network benefits, $c=0.1$

will migrate if the gain in profits outweighs migration costs:

$$
\frac{1}{2} c<\frac{1}{2}(b-\sqrt{D})
$$

For $c=0.1$, the resulting relationship is shown by the solid line in figure $2 .{ }^{12}$ Compared to the lower curve in figure 1 , migration costs shift the curve upwards, increasing the area where firms prefer to maintain incompatible versions. On the other hand, migration costs reduce the welfare gain of establishing compatibility. The dotted-line curve in figure 2 represents the points where the net effect on social welfare is neutral because migration costs just offset the welfare gain of compatibility:

$$
c=\frac{\delta}{2} b
$$

The preference of firms to maintain incompatibility leads to a social loss only in the area between the two curves. And for $\delta$ sufficiently small, 'excess inertia' (firms prefer incompatibility while migration would raise social welfare) is no longer a social problem.

${ }^{12}$ After some reshuffling expression (7) can be reworked to:

$$
b=\frac{c-2 \delta+2-2 \sqrt{\delta^{2}-\delta c-2 \delta-2 c^{2}+c+1+3 \delta c^{2}-c^{2} \delta^{2}}}{9-12 \delta+4 \delta^{2}}
$$

This relationship is shown in the graph. 
Result 4 Migration costs mitigate the issue of welfare loss, especially if transaction patterns are highly autarkic (small $\delta$ ).

Since migration costs represent real costs, they reduce the welfare loss of maintaining incompatibility. This is especially the case if $\delta$ is very small: the benefits of a common standard are then quite small relative to the cost of migration. It is therefor not surprising that the net welfare benefit of migration to a compatible standard is negative if transaction patterns are highly autarkic. As before, however, this does not consider reduced X-inefficiencies caused by increased competition. If these are taken into account, welfare gains of compatibility would increase and the dotted line in figure 2 would shift downwards.

\section{Application to European payments}

Payments offer an interesting application of the model results. Three types of instruments were distinguished in table 1: cash, card payments (including ATM withdrawals), and credit transfers.

While cash was indeed harmonized with the introduction of the Euro, the instrument is not a commercially sponsored standard (the sponsoring central banks are not profit focused); therefore the model of the previous section cannot be applied to cash.

In the case of cards, the purely technical compatibility issues are minor. All ATMs can accept practically all cards from all countries, and the same is true for most POS terminals. Yet banks have maintained largely national card systems. Most countries have national schemes, such as Bancontact/MisterCash in Belgium and EC Cash in Germany. While these cards can be used at foreign Point of Sales using the Maestro function, most merchants only accept the domestic cards. And banks charged (much) higher fees on cross-border card transactions than on domestic transactions, until this practice was prohibited by the EU in 2002. Arguably, the current set-up does make it impossible for a Belgian bank to sign up Dutch customers, unless that bank sets up a Dutch operation that joins the local processing network, supports the Dutch protocols, etc.

For international credit transfers, the technical incompatibility issues run deeper than in cards. Each country has its own account numbering system, and credit transfer format. And an instrument like direct debit is subject to very different rules in various countries. ${ }^{13}$

\footnotetext{
${ }^{13}$ These rules have to do with things like consumer protection: can an automatic debit be reversed by the consumer? Up till how many weeks after the transaction?
} 
This lack of standardization in credit transfer payments became quite visible with the introduction of the physical Euro in 2002, which created a single (cash) payment instrument that could be used throughout 12 EU countries. By that time, the European Commission had been urging banks to improve the situation for several years, as it considered the lack of a proper Pan-European payments infrastructure an impediment to the further integration of Europe. From 1990 to 2000 a series of white papers and Directives urged banks to take action, all to little avail. ${ }^{14}$ Increasingly frustrated with this lack of progress, the European Parliament passed Regulation EC 2560/2001 (European Community, 2001). This regulation forced banks to maintain the same tariff structure for domestic and international Euro payments below EUR 12,500, and to implement a common account numbering system (IBAN).

Reality is of course far more complex than the 2-firm model laid out in the previous section. Nevertheless, it offers some basic insights into the compatibility and harmonization decision for semi-autarkic networks. As shown in the introduction, payments networks exhibit precisely such transaction patterns.

Let $f$ denote cross-border transactions as a share of all transactions. As summarized in table $1, f^{\text {cards }} \approx 5 \%$ and $f^{\text {transfers }} \approx 0.5 \%{ }^{15}$ These quantities give an indication of the value of the parameter $\delta$. The duopoly model of the previous section put the share of foreign transactions at $f=\frac{\delta}{2}$. In a more general setting, with $N$ countries with shares $s_{i}, i=1 . . N$, the share of foreign transactions, denoted $f_{i}$, is equal to:

$$
f_{i}=\delta\left(1-s_{i}\right)
$$

Summing across all countries we get:

$$
f=\sum_{i=1}^{N} s_{i} f_{i}=\delta(1-H)
$$

where $f$ is the overall share of cross-border transactions and $H=\sum s_{i}^{2}$ is the Herfindahl index. If we approximate the $s_{i}$ for European countries

\footnotetext{
${ }^{14}$ For an overview, see European Commission (2000).

${ }^{15}$ Estimate of $f^{\text {transfers }}$ is based on data from BIS (2004) and ECB (2003). Crossborder transfers are estimated from number of swift category-1 messages. The total number of transfer transactions was based on the sum of direct debits, domestic transfer payments, half of all checks (assuming the other half was written at the POS) and cross-border transfers. Estimate of $\delta^{\text {cards }}$ based on data from Visa and MasterCard.
} 
by their population share, we get $H=0.14$, and

$$
\begin{aligned}
\delta^{\text {transfers }} & =\frac{f^{\text {transfers }}}{1-H} \approx \frac{0.5 \%}{0.86} \approx 0.6 \% \\
\delta^{\text {cards }} & =\frac{f^{\text {cards }}}{1-H} \approx \frac{5 \%}{0.86} \approx 6 \%
\end{aligned}
$$

Obtaining an estimate for $b$ is trickier, because $b$ is expressed as a multiple of $t$, the transportation costs in the Hotelling model, which is clearly an unobserved variable. We can conclude however, that the low values of $\delta$ put us clearly on the far left of figures 1 and 2. Finally, one could assume that for cards the costs of moving to a technically compatible system is small: $c \approx 0$, while in credit transfer payments $c$ could be substantial.

Overall, the current landscape in both instruments is in line with Results 1 and 2: perfect compatibility within countries, and much more limited compatibility across countries. Given the low $\delta$, one could argue that for cards the overall welfare loss due to this cross-border incompatibility is limited, while it increases bank profits at the expense of consumers. As said, per customer migration costs might be significant for credit transfer payment systems. According to Result 4, this would further decrease any welfare loss, especially since $\delta^{\text {transfers }}$ is very low indeed. The welfare transfer effect, however, could be quite relevant. Finally, one expects the reluctance of banks to establish compatibility to be much larger for credit transfers than for cards: they would have to bear any migration costs, while the positive effect of incompatibility on profits is larger than for cards, because $\delta^{\text {transfers }}$ is much lower than $\delta^{\text {cards }}$.

The EC Regulation indeed achieves a wealth transfer (back) from banks to consumers, by forcing lower rates on cross-border credit and debit card and credit transfer payments. But it has not (yet) led to fully compatible systems, especially in credit transfer payments. Banks responded to the EC Regulation by agreeing to establish at least one (EBA step2), and possibly more, Pan European Automated Clearing Houses (PEACHs). However, these were primarily envisioned as a solution for cross-border payments, acting as an overlay for the domestic systems. While eventually some domestic volumes might migrate to this $\mathrm{PEACH}$, this was not foreseen for the short or even medium term. ${ }^{16}$ Given the substantial costs of migrating all domestic systems to a common infrastructure, account numbering system etc., this decision makes perfect sense from the point of views of banks. And it is in line with

\footnotetext{
${ }^{16} \mathrm{EBF}(2002)$.
} 
the dynamics of the model of section 3. However, it also means that national payment systems will continue to be one of the (many) barriers to European banking integration.

\section{Discussion of results}

This paper analyzes the compatibility decision for network products with sponsored standards in the presence of (somewhat) autarkic transaction patterns. A simple 2-firm model showed that transaction patterns can be very relevant for the compatibility decision. National transaction patterns may lead firms to prefer compatibility within, and incompatibility across countries. The basic reason for this is that incompatible networks act as a barrier between countries, giving firms a certain degree of monopoly power in their home country.

For the sake of simplicity, the model focusses on transaction patterns at the expense of other aspects. Importantly, it uses the Hotelling framework which assumes fixed demand and takes firm costs as given. As discussed, the former assumption may be reasonable in the case of payments, but the latter is more dubious. The benefits of migrating to a common standard may therefor be substantial, even if direct welfare gain is limited due to the low number of cross-border transactions and likely migration costs. There may thus be a clear divergence between the interests of banks and a social planner. This is a fortiori the case if the benefits of increased trade in European goods and services (due to cheaper/simpler cross-border payments) are considered.

Several areas remain to be further explored. On the empirical side, it would be fascinating to analyze transaction patterns within countries, for example between individual USA states or German Länder. Is there comparable autarky at this level? On the theoretical side, the model could be expanded to deal with multiple firms within a country that compete against each other, as well as against firms in the other country.

\section{References}

Bassanini, A. P. and G. Dosi, 1998, Competing technologies, international diffusion and the rate of convergence to a stable market structure, IIASA interim report, no. IR-98-012.

Berger, A.N., R. DeYoung, H. Genay and G.F. Udell, 2000, Globalization of financial institutions: evidence from cross-border banking performance, Brookings-Wharton papers on financial services, vol 3 . 
BIS, 2004 and previous years, Statistics on payment and settlement systems in selected countries (red book), Bank for International Settlements, Basel.

DePalma, A. and L. Leruth, 1993, Equilibrium in competing networks with differentiated products, Transportation Science 27/1: $73-80$.

Cecchini, 1988, The European Challenge 1992, the benefits of a single market, Gower House, Aldershot, UK.

Cowan, R. and W. Cowan, 1998, Technological standardization with and without borders in an interacting agents model, Merit research memorandum \# 2/98-018.

EBF, 2002, Euroland: our single payment area!, European Banking Federation, European Savings Banks Group, et al., White paper. Brussels.

ECB, 2003, Statistics on payment and settlement systems in EU countries with 2001 figures (blue book), ECB, Frankfurt.

Ellison, G.,1993, Learning, local interaction, and coordination, Econometrica 61/5: 1047-1071.

European Commission, 2000, Commission plans to clear certain Visa provisions, challenge others, Press release IP/00/1164.

European Community, 2001, Regulation on cross-border payments in Euro, Regulation no. 2560/2001.

Gowrisankaran, G. and J. Stavins, 2002, Network externalities and technology adoption: lessons from electronic payments, NBER Working Paper No. 8943.

Hoschka, T.C., 1993, Cross-border entry in European financial services: determinants, regulation and the impact of competition. Macmillan, London.

Humphrey, D. B., L. B. Pulley, et al., 1996, Cash, paper, and electronic payments: a cross-country analysis, Journal of Money, Credit and Banking 28/4: 914-939.

Humphrey, D. B., M. Kim, et al., 2001, Realizing the gains from electronic payments: costs, pricing, and payment choice, Journal of Money, Credit and Banking 33/2: 216-234.

Kleimeier, S. and H. Sander 2003, European financial market integration: evidence on the emergence of a single Eurozone retail banking market, Research in Banking and Finance 3: 13-19. 
Matutes, C. and P. Regibeau, 1988, 'Mix and match': product compatibility without network externalities, RAND Journal of Economics 19/2: 221-234.

Mantel, B. and T. McHugh, 2001, Competition and innovation in the consumer e-payments market? Considering the demand, supply, and public policy issues, Emerging Payments Occasional Working Paper Series, December 2001 (EPS-2001-4), Federal Reserve Bank of Chicago.

Murphy, N. B., 1991, Determinants of household check writing: the impacts of the use of electronic banking services and alternative pricing of services, Financial Services Review 1-Jan: 35-44.

Saloner, G. and A. Shepard, 1995, Adoption of technologies with network effects: an empirical examination of automated teller machines, RAND Journal of Economics 26/3: 479-501.

Sharma, S., 1993, Behind the diffusion curve, UCLA department of economics. Working paper \#686.

Shy, O., 2001, The economics of network industries. Cambridge University Press.

Stavins, J., 2001, Effect of consumer characteristics on the use of payments instruments, New England Economic Review(3): 1931.

Telestatistik, 2000, Telecom statistics, first half of 2000, National Telecom Agency, Denmark.

TeliaSonera, 2004, ProForma Operational Data Q1-Q3, available through www.teliasonera.se.

UPU, 2004, Universal Postal Union mail database, Berne, Switzerland, accessible through www.upu.int.

\section{Appendix: Model outcomes for $\delta<1$}

To find equilibrium outcomes for the model with autarkic transaction patterns, this appendix first derive market share functions, then uses these to calculate response functions and equilibrium prices and profits.

1. Market share functions. If $\delta<1$, the market share functions are no longer continuous, if firms have incompatible standards. To see that, take the perspective of firm 2, as it tries to expand market share beyond $s_{2}=\frac{1}{2}$. Attracting the nearest customer in the other 'country' requires a discontinuous lowering of price, since the network benefits for that customer are limited: he interacts mostly with customers of country 1 , 
who use the incompatible network of firm 1 . The network benefits of the 'last' customer in country 2 are equal to:

$$
\left(1-\frac{\delta}{2}\right) b
$$

since he performs a fraction $\frac{\delta}{2}$ with 'foreign' customers and thus a fraction $\left(1-\frac{\delta}{2}\right)$ with domestic customers, and only domestic customers use his network. The network benefits of the first 'foreign' customer of firm 2 (located in country 1) are equal to:

$$
\frac{\delta}{2} b
$$

since this customer can only use the network of firm 2 for his foreign transactions. Thus, to attract the first foreign customer, the price needs to drop by the difference between (8) and (9) or:

$$
\left(1-\frac{\delta}{2}\right) b-\frac{\delta}{2} b=(1-\delta) b
$$

Hence all prices that satisfy $\left|p_{1}-p_{2}\right| \leq(1-\delta) b$ will lead to $s_{1}=s_{2}=\frac{1}{2}$ (note that if $\delta=1$, the required drop is 0 , and the function is continuous). Assume $p_{2}<p_{1}-(1-\delta) b$. In that case the marginal customer, with address $s_{1}$, will reside in country 1 . By definition the address of this marginal customer is $s_{1}$. Of all his transactions, a share $\left(1-\frac{\delta}{2}\right)$ is with customers in country 1 . Of these, a fraction $2 s_{1}$ are using the network of firm 1 . Hence a share of his transactions equal to $\left(1-\frac{\delta}{2}\right) 2 s_{1}=(2-\delta) s_{1}$ is with customers on network 1 and $1-(2-\delta) s_{1}$ is with customers on network 2. Now for this marginal customer the benefits of both networks need to be the same:

$$
p_{1}+t s_{1}-b(2-\delta) s_{1}=p_{2}+t\left(1-s_{1}\right)-b\left[1-(2-\delta) s_{1}\right] .
$$

Normalizing $t=1$ and solving for $s_{1}$ :

$$
\begin{aligned}
2 s_{1}-2 b(2-\delta) s_{1} & =p_{2}-p_{1}+1-b \Leftrightarrow \\
s_{1} & =\frac{p_{2}-p_{1}+1-b}{2-2 b(2-\delta)} .
\end{aligned}
$$

Using a similar approach for the case where the marginal customer is in country 2 , we get the following share function for $s_{1}$ (and $s_{2}=1-s_{1}$ ):

$$
\begin{aligned}
\text { if }\left|p_{1}-p_{2}\right| \leq(1-\delta) b: & s_{1}=\frac{1}{2} \\
\text { if } p_{1}-p_{2}>(1-\delta) b: & s_{1}=\frac{p_{2}-p_{1}+1-b}{2-2 b(2-\delta)} \\
\text { if } p_{2}-p_{1}>(1-\delta) b: & s_{1}=\frac{p_{2}-p_{1}+1-b(3-2 \delta)}{2-2 b(2-\delta)} .
\end{aligned}
$$


2. Equilibrium prices and profits. We now get a situation where a firm can only expand its market share above $\frac{1}{2}$ if it substantially drops its price, 'undercutting' its rival. To analyze this type of situation I use the concept of Undercut Proof Equilibrium (UPE), described in Shy (2002). It defines equilibrium as a situation where neither firm can profitably undercut its rival's price. Let $\pi_{i}^{*}, p_{i}^{*}$ and $s_{i}^{*}$ denote UPE profits, prices and shares. Because of the symmetry $s_{1}^{*}=s_{2}^{*}=\frac{1}{2}$. Suppose firm 2 tries to undercut its rival, who is charging $p_{1}^{*}$, by offering a price $p_{2}$. We can now maximize firm 2 profits: $\pi_{2}=\left(p_{2}-c\right) s_{2}$. The first order condition is:

$$
\begin{aligned}
\frac{\partial \pi_{2}}{\partial p_{2}} & =s_{2}+\left(p_{2}-c\right) s_{2}^{\prime}=0 \Leftrightarrow \\
p_{1}^{*}-p_{2}+1-b(3-2 \delta) & =p_{2}-c \Leftrightarrow \\
p_{2} & =\frac{p_{1}^{*}+1-b(3-2 \delta)+c}{2} .
\end{aligned}
$$

If firm 2 indeed selects this price $p_{2}$ we get:

$$
\begin{aligned}
& s_{2}=\frac{p_{1}^{*}-p_{2}+1-b(3-2 \delta)}{2-2 b(2-\delta)}=\frac{\frac{p_{1}^{*}+1-b(3-2 \delta)-c}{2}}{2-2 b(2-\delta)} \\
& \pi_{2}=\left(p_{2}-c\right) s_{2}=\frac{\left[\frac{p_{1}^{*}+1-b(3-2 \delta)-c}{2}\right]^{2}}{2-2 b(2-\delta)} .
\end{aligned}
$$

If firm 2 were to charge $p_{2}^{*}=p_{1}^{*}$ (instead of undercutting firm 1 ), its profit would be $\left(p_{1}^{*}-c\right) \frac{1}{2}$. So a price $p_{1}^{*}$ is undercut proof if firm 2 cannot get a higher profit by deviating form $p_{2}=p_{1}^{*}$ :

$$
\begin{aligned}
& \frac{\left(p_{1}^{*}-c\right)}{2} \geq \pi_{2} \\
& \frac{\left(p_{1}^{*}-c\right)}{2} \geq \frac{\left[\frac{p_{1}^{*}+1-b(3-2 \delta)-c}{2}\right]^{2}}{2-2 b(2-\delta)}
\end{aligned}
$$

We can directly substitute $\pi_{1}^{*}=\left(p_{1}^{*}-c\right) \frac{1}{2}$ to obtain:

$$
\begin{aligned}
{[2-2 b(2-\delta)] \pi_{1}^{*} } & \geq\left[\pi_{1}^{*}+\frac{1-b(3-2 \delta)}{2}\right]^{2} \Leftrightarrow \\
0 & \geq\left(\pi_{1}^{*}\right)^{2}-(1-b) \pi_{1}^{*}+\left[\frac{1-b(3-2 \delta)}{2}\right]^{2} .
\end{aligned}
$$

$\pi_{1}^{*}$ is the highest value that satisfies this quadratic inequality. Hence:

$$
\begin{aligned}
\pi_{1}^{*} & =\frac{1-b+\sqrt{D}}{2} \text { with } \\
D & =(1-b)^{2}-[1-b(3-2 \delta)]^{2} .
\end{aligned}
$$


Because of symmetry, $\pi_{1}^{*}=\pi_{2}^{*}$. Note that if $\delta=1$ (the case analyzed in section 3 ) we get $D=0$ and $\pi_{i}^{*}=\frac{1}{2}-\frac{b}{2}$, which is exactly the result obtained in section 3 (table 1). Hence the concept of UPE converges to the standard Hotelling Nash-equilibrium as $\delta \rightarrow 1$ (as it should). 